\title{
Effect of Linguistic Context on the Perception of Consonants in Parkinsonian Read French Speech
}

Duez Danielle $^{1}$, Ghio Alain ${ }^{1}$, Viallet François ${ }^{1,2}$

(1) Aix-Marseille Univ, CNRS, LPL, Aix-en-Provence, France

(2) Centre Hospitalier du Pays d'Aix, Service de Neurologie, Aix-en-Provence, France

* Corresponding Author:

Danielle Duez

Aix-Marseille Univ, CNRS

Laboratoire Parole \& Langage

5 avenue Pasteur

BP 80975

13604 Aix en Provence Cedex 1

France

Tél : +33 (0)4 13553634

email : danielle.duez@lpl-aix.fr 


\section{Acknowledgements}

The authors would like to thank all of the participants to this study. We also thank Alain Purson and Ludovic Jankowksi for assisting with patient recordings. The authors thank the CEP staff (www.lpl-aix.fr/ cep), Laura Reynaud, and Carine André for assisting in perceptual experiment. The authors thank Rachael Renié-Phillips (SWIFT \& TRUE TRADUCTIONS) for her work on correcting English in the text.

\section{Funding Sources}

This research was partially funded by LPL (BQR2017) and by the French National Research Agency ANR-18-CE45-0008 "Looking for relevant linguistic units to improve the intelligibility measurement of speech production disorders". 


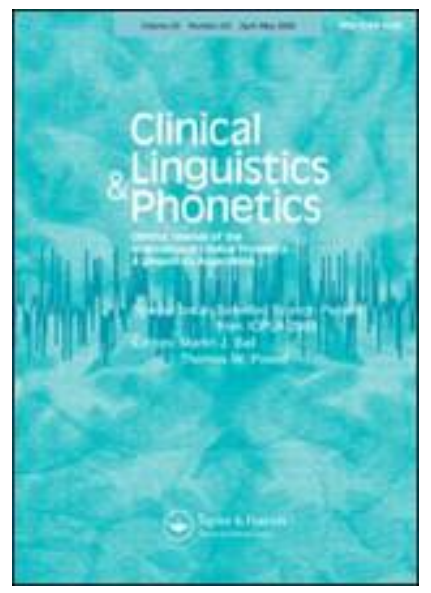

\section{Effect of Linguistic Context on the Perception of Consonants in Parkinsonian Read French Speech}

\begin{tabular}{|r|l|}
\hline Journal: & Clinical Linguistics \& Phonetics \\
\hline Manuscript ID & TCLP-2020-0107.R1 \\
\hline Manuscript Type: & Original paper \\
\hline Keywords: & $\begin{array}{l}\text { parkinsonian speech, linguistic context, consonants, perception, speech } \\
\text { assessment }\end{array}$ \\
\hline \multicolumn{2}{|l}{} \\
\hline
\end{tabular}

\section{SCHOLARONE \\ Manuscripts}




\title{
Effect of Linguistic Context on the Perception of Consonants in Parkinsonian read French Speech
}

\begin{abstract}
We examined the effect of linguistic factors on the perceptual identification of intervocalic consonants produced by speakers with Parkinson's Diseases (PD). To neutralize the effect of preceding and following contexts, all the intervocalic consonants were excised with half the preceding and following vowels.

We recorded $10 \mathrm{PD}$ and 10 healthy speakers reading a text. An average of $114 \mathrm{VCV}$ sequences per speaker was obtained. In total, our corpus consisted of 2280 stimuli. For the perception test, 20 adults native speakers of French were instructed that they would be presented utterances produced by different speakers and that they were to identify the sequences and write what they heard. No information was given on the sequence type (VCV).
\end{abstract}

The reported consonant was examined in relation to the intended consonant; the score of distorsion was the number of phonetic features differing from the prototypical consonant. The results were examined as a function of the following/or preceding linguistic factors : consonant nature, oral/nasal vocalic context, class of word (function or content) and prosodic position within sentences.

Consonant imprecision was confirmed in the speech of PD speakers. Two groups of patients were observed : the former with a low degree of dyarthria severity and scores of consonant identification close to that of healthy speakers; the latter with a high degree of dysarthria severity and a low identification score. 
Linguistic factors were shown to affect consonant production and perception. In both normal and PD speech, consonants had more features identified when they belonged to content words, word-initial syllables or final-phrase syllables. This suggests that in Parkinson's disease speech disorders relate to motor control and not to a loss of the linguistic knowledge.

Keywords : parkinsonian speech, linguistic context, consonants, perception, speech assessment 


\section{Introduction}

Parkinson's disease (PD) is characterised by a progressive loss of dopaminergic neurons within the substantia nigra (pars compacta); its external manifestations are movement deficits including rigidity or stiffness (muscles resistant to movement), akinesia (inability to initiate movement), rest tremor and bradykinesia (slowness of movement). Concerning bradykinesia one must observe that this cardinal motor symptoms of PD is particularly complex: it seems to arise from netword dysfunction, this of the basal ganglia and other interconnected structures, such as the primary motor cortex and cerebellum, as well as the contribution of abnormal sensorimotor processing (for more details see Bologna et al., 2020)

Resultant problems in speech production, known as Parkinsonian dysarthria or hypokinetic dysarthria, affect respiration, prosody and articulation (Darley et al., 1969). Patients with PD typically exhibit deficits in speech production which are reflected on an acoustic level by changes and anomalies in fundamental frequency $\left(\mathrm{F}_{0}\right)$, intensity, rate of speech, duration and distribution of pauses and consonant imprecision.

Consonant imprecision which has been identified as one of the most common disturbances of PD speech has been examined in a certain number of perceptual, acoustic and physiological studies. For example, in a study using the Fisher-Logemann Test of Articulation Competence (Fisher and Logemann, 1971), Logemann and Fisher (1981) investigated the phonetic transcription made by two experts of the articulation patterns of 200 PD patients; they observed that manner changes predominated and that the stop-plosives, the affricates, and the fricatives were the most affected, they also stated there was a posterior-anterior progression in articulatory breakdown in PD speech. In terms of perception features (Chomsky \& Halle, 1968), the stopplosives and affricates, which are normally [-continuant] were produced as [+continuant] fricatives; fricatives that are [+strident] were produced as [-strident $]$. 
More recently, Read et al. (2018) partially replicated Logeman and Fisher's study to check whether there was an order in the loss of sounds in PD speakers. They examined the speech produced by ninety-nine people with PD in a diagnostic intelligibility test where 60 listeners unfamiliar with PD had to score various speech sounds. They calculated the proportion of posterior vs anterior lingual vs labial sounds misrecognized by the listeners. They did not report evidence supporting the existence of a posterior to anterior order of 'loss' of oral speech sounds in people with PD and observed that findings were more compatible with an underlying pathology that affects all places of articulation.

Consonant imprecision was also reported in a perceptual study on speech characteristics of a group of 19 subjects with mild-moderate Parkinson's Disease (PD) compared with those of normal non-neurologically impaired control (Chenery et al., 1988). In this study, deficits were found in all aspects of speech production; however, the speech deviation which contributed most to the variance in overall intelligibility of speech was the imprecision of consonant articulation. Similarly, in a perceptual study on the speech parameters of two-minute conversations produced by a large sample of patients with Parkinson's disease, two trainedraters judged that articulatory and fluency deficits manifested at the 'Severe' stage. At the final stage 'Profound' impairment, articulation was the most frequently impaired feature at the lowest level of performance (Ho et al., 1999)

Sound imprecision has also been confirmed in studies on the impact of levodopa on perceptual characteristics of Parkinson. In a study of American PD speech, where readings of patients in OFF and ON state were submitted to three raters, sound imprecision was reported as the most deviant speech characteristic (Plowman-Prine and al., 2009). 
The acoustic evidence obtained in PD speech in various languages is in accordance with the above results. For example, in a spectrographic analysis of the speech produced by two PD speakers, Kent and Rosenbek (1982) observed a tendency towards continuous voicing and the replacement of voiceless segments by voiced ones. Similarly, Weismer (1984) reported a strong tendency for PD speakers to produce voiceless stops with voicing continuing into the closure interval.

Recent studies on stop consonants in American English looked at the occurrences of bursts (the moment of release) and multiple bursts in initial stop consonants produced by nine individuals with PD (ON and OFF medication) and nine control speakers (Parveen and Goberman, 2014). Compared to controls, for individuals with PD there was loss of bursts in bilabial stops and more multiple bursts in alveolars. In addition, no dopamine-related medication effects were found for occurrences of bursts or multiple bursts in individuals with PD. The impact of motor deficits on the production of consonants was also demonstrated in a study of the VOT (the time interval between the burst and the onset of voicing) obtained from a group of speakers with PD with both ON and OFF medication, and a group of healthy controls (Whitfield and al., 2018). Individuals with PD exhibited significantly less contrast between the VOT of voiced and voiceless stops than that observed in healthy speakers; in addition there was no effect of medication. The authors suggested that dysfunction associated with PD may disrupt the timing of the voicing gesture, leading to aberrant timing of the voicing onset that is essential for stop consonant contrast.

Anomalies were also reported in studies on French consonants. In an oscillographic study of the speech produced by two French dysarthric groups (pseudo-bulbar and PD) Gremy (1958) observed articulatory anomalies for the PD group with the voicing of voiceless intervocalic consonants and the devoicing of initial-syllable consonants. Uziel and al. (1971) observed 
similar tendencies in a spectrographic study with the voicing of voiceless stops, the hypervoicing of voiced consonants and the devoicing of some voiced stops. Similar characteristics were found in a comparison of PD and control speech in French, in addition a greater absence of bursts was observed in PD speech and a tendency for voiced stops to become approximants (Duez, 2014). As suggested by Kent and Netsell (1975), continuous voicing may represent compensatory behavior, which allows the speaker to avoid starting and stopping difficult articulatory gestures. Spirantization has also be shown to be a salient feature of consonant imprecision in PD speech. Stop gaps were found to be replaced by low-intensity frication, this reflecting the failure of complete oral closure (Kent and Rosenbek, 1982; Weismer, 1984).

More recently, in an acoustic study of the speech produced by 12 German patients, Ackermann and Ziegler (1991) observed a reduced capacity in completing articualory occlusion for stops and interpreted this as a reduction in movement amplitude of the articulators. They also found that this articulatory "undershoot" was not uniform but influenced by linguistic demands, closures associated with stressed syllables being performed at the expense of unstressed ones.

The results reported above indicate a clear correspondance between perceptual and acoustic characteristics of consonants in PD speech. As the information contained in the speech signal is crucial for lexical access, this raises the question of the intelligibility of dysarthric speech. Many of the studies on speech intelligibility have investigated specific phonetic contrasts in minimally differing words (see for example, Kent et al, 1989; Read et al., 2018). Others were based on pseudo-words in order to neutralize the effect of contextual information which may help the listener to restore distorted sequences (Lalain et al., 2020). 
These studies allow to focus on the acoustic-phonetic features which are particularly sensitive to dysarthric impairement and contribute to speech intelligibility however as single words or pseudo-words were mostly used in carrier phrases or short sentences and not in continuous speech, the variability resulting from the impact of various linguistic factors was not considered.

The present study was aimed at investigating the impact of linguistic factors on the perception of all the intervocalic consonants contained in a paragraph read by 10 PD speakers and 10 healthy speakers. Chosing to use a paragraph allows us to examine a great variety of consonants produced in different types of words (content versus function words), and in different positions within phrases (word-initial syllables, final-phrase syllables or within-phrase syllables). The effect of vowel context (nasal/oral) was also examined: as hypernasality has been reported for PD patients (Novotný et al., 2016) it was found interesting to see how this hypernasality interacts with the production of oral and nasal vowels. The perceived features were compared in various contexts in both groups, it was assumed that this comparison will allow us to focus on Parkinson's disease effects and tell us whether the patients analysed here could preserve the linguistic information necessary to speech communication in spite of their motor problems. To neutralize the effect of preceding and following contexts which help to restore the information missing in imprecise or reduced consonants (Duez, 2001), all the intervocalic consonants were excised with half the preceding and following vowels in both PD and control groups. Interestinly, this allows us to test the procedure and see whether VCV sequences might be used in the analysis of pathological speech intelligibility. 


\section{Subjects and Methods}

\section{Corpus}

The corpus used to make the stimuli was a paragraph from "La chèvre de Monsieur Seguin, $\mathrm{Mr}$ Seguin's goat" (a tale written by Daudet, 1869) read by 10 male individuals diagnosed with Parkinson's disease and 10 age-and-gender-matched healthy control speakers. Each subject was asked to read the text held by a research assistant at his usual speech rate. High-quality recordings were obtained in a sound-treated room of the Aix-en-Provence Hospital. The acoustic signal was transduced using an AKG C410 head-mounted microphone and recorded with EVA2 (Ghio, et al., 2012). The distribution of consonants used as stimuli in healthy control and patient speech are detailed in Table 1.

\section{INSERT TABLE 1}

\section{Patient and control speakers}

From the Speech Disorder Database "Speedi-DB" (Ghio et al., 2012), we selected 20 native French male speakers including 10 individuals diagnosed with Parkinson's disease (mean age : 55) and 10 age-and-gender-matched healthy control speakers (mean age :60). The patients were between 6 and 26 years post-diagnosis (Mean :13.1) recorded in the Department of Neurology at the hospital of Aix-en-Provence. They had no history of neurological, respiratory, laryngeal, speech and voice diseases or disorders, apart from those associated with PD, they were being treated with L-Dopa and were experiencing motor fluctuations in response to their treatment. They had adequate vision with corrective lenses and claimed not to suffer from hearing loss. In order to make the effects of PD more discernable, anti-Parkinsonian medications were withheld overnight and the first recordings started after at least 12 hours without medication. Before recording, the motor disability of each patient was assessed using the Unified Parkinson's 
Disease Rating Score (UPDRS), especially dysarthria severity as defined by item 18 (Fahn et al., 1987). The characteristics of each speaker are listed in Table 2.

Patients were recorded between 1998 and 2008 during a PHRC Program (Programme Hospitalier de Recherche Clinique) approved by the ethical commission. All subjects gave their informed and written consent.

\section{INSERT TABLE 2}

\section{Stimuli}

As above mentioned, the importance of contexts has been shown by Pickett and Pollack (196364) who demonstrated in a series of studies that when a word is extracted from its context provided by other words, it is less intelligible; in turn, the intelligibility of this word improves as the duration of the sample is increased by adding succeeding words. More recently, the role of contexts has been demonstrated in a study dealing with the restoration of $\mathrm{VC} 1 \mathrm{C} 2 \mathrm{~V}$ sequences extracted from conversational speech (Duez, 2001). Consonants were presented with their left context then with both their left and right context, contexts being incremented syllable by syllable. The results indicated that about $80 \%$ of the consonants were restored at the breath group level. Therefore to neutralize the effect of contexts, the intervocalic consonants which had previously been identified, labeled and segmented (Duez, 2009) were excised with half their immediate adjacent preceding and following vowels. An example of stimuli can be seen Figure 1. This method which has already been used in a study of the hypoarticulation of voiceless plosives in spontaneous speech (Duez, 1995-98) allows us to focus on the information retained in the consonant.

An average of $114 \mathrm{VCV}$ sequences per speaker was obtained. Consequently, our corpus consisted on 2280 stimuli (20 speakers * 114). 


\section{INSERT FIGURE 1}

\section{Listeners}

The 2280 stimuli were divided randomly into 20 blocks. A block is made up of 114 elements that can come from all speakers. These stimuli were submitted to twenty adult native Frenchspeaking listeners who were recruited for the experiment. They have no problems of hearing loss, they have given their written informed consent and were paid 10 euros each. They were instructed that they would be presented utterances produced by different speakers and that they were to identify the sequences and write what they heard. No information was given on the sequence type (VCV). These tests took place in the «Centre d'expérimentation sur la parole » (Center of Speech Experimentation, www2.lpl-aix.fr/ cep/) in the Speech and Language Laboratory in Aix-en-Provence with the computer-driven system for experimentation PercevalLancelot (André et al., 2003).

Each listener, wearing Superlux HD 681B phonic headphones, transcribed 3 blocks of 114 items, i.e. 342 stimuli (Table 3). The listener could preset the sound playback intensity in order to be comfortable for the task. Each test started with four training stimuli. Each item was presented once automatically but the listener could repeat the playback twice. The listener had a pause of 5 minutes between the blocks. A total of 6840 responses were collected because each block was submitted to 3 different listeners.

\section{INSERT TABLE 3}

\section{Pre-processing and scoring}


Once the orthographic transcriptions were collected, the responses were analyzed manually in order to obtain the phonotactic structure of the response and above all to identify the consonant perceived. In term of structure, there were $67 \% \mathrm{VCV}$ 's reported as VCV's, $13 \% \mathrm{VCV}$ 's reported as CV's, 2\% as VCCV. In the latter case the /d/ or $/ \mathrm{t} /$ was affricated before a front vowel such as $[\mathrm{i}, \mathrm{u}]$, the /d/ was produced as $[\mathrm{dz}]$, the /t/ as [ts or $\mathrm{t}]$, some phonetic environments being favourable to the development of phonetic affricates in contemporary French (Berns, 2013). The remaining 2\% CVC's were reported as CVCV's. In other cases, listeners could not identify the consonant and did not write anything.

In certain cases, listeners perceived VCV's as words. For example, the sequence [e $\left.\int \mathcal{E}\right]$ was reported as [efEl] ("echelle" in French, ie "ladder" in English), the sequence [ãze] as [mãze] ("manger" in French, ie "to eat" in English).

We focused on consonants and did not take care of the transcription of the vowels. The orthographic form was simplified as a phonetic form. For instance, in French, the orthographic sequence "ph" was phonetized as [f], "g"+"e" was phonetized as [3]. The grapheme to phoneme conversion in French is consistent and we kept only the data where there was no ambiguity (we erase only 18 ambiguous responses over 6819).

The reported consonant was examined in relation to the intended consonant. We call Perceived Phonological Deviation score (PPD) the number of phonetic features differing from the prototypical consonant to the response. A score of 0 means that the consonant was correctly identified. A score of ' $\mathrm{N}$ ' means that there was ' $\mathrm{N}$ ' phonological features misidentified. The phonetic features of French consonants are described in (Ghio et al., 2020). 
For each consonant, the PPD score was calculated automatically (Ghio et al., 2020). For instance, if a ' $p$ ' was perceived as ' $k$ ', the PPD score was 2 , if a ' $v$ ' was perceived as ' $g$ ' the PPD score was 3.

Finally, the average score of a speaker was the mean of all the scores obtained for all the consonants they produced. Then the results were examined as a function of the following linguistic factors : consonant, oral/nasal vocalic context, word class and position within sentences.

\section{Contexts as factors of variation}

The results were examined for each consonant produced by the speakers.

Nasal/oral vocalic context

The study of vocalic context was limited to nasal and oral contrast for two reasons. The first is that French is specific in possessing three nasal vowels ( $\tilde{\mathrm{o}} \tilde{a} \tilde{\varepsilon})$, world languages with nasal vowels being in minority (150 out of 700, according to Ruhlen (1975). The second is that nasal vowels have been shown to impact the production of certain consonants. For example, when preceded and/or followed by a nasal vowel, voiced stops may be partially or totally nasalized : in case of partial overlapping of the velum lowering gesture and the occlusion, the consonant is partially nasalized; in case of a complete overlapping of the occlusion and the velum lowering, the consonant is totally nasalized with a $/ \mathrm{d} /$ perceived as $/ \mathrm{n} /$ and a $/ \mathrm{b} /$ perceived as $/ \mathrm{m} /($ Duez, 1995). Parkinson's disease is characterised by the rigidity of the velum and nasality has been shown to be a strong perceptual feature in differentiating the speech of patients and this of control speakers (Ludlow and Bassich, 1983). Therefore, it was considered interesting to examine each consonant report as a function of the oral or nasal vocalic context. 


\section{Class of Word}

Words can be classified either as content words or as function words. Content words express lexical meanings, they name and characterize objects and persons and constitute an open class with new words invented regularly. Content words with low predictibility are produced with more care than content words with high predictibility predictibility (Lieberman, 1963; Hunnicut, 1985; Fowler and Housum, 1987). Function words constitute a closed word class, they contain information which can be inferred from the context, they tend to be reduced or deleted more often than content words (Van Bergem, 1993; Johnson, 2004; Meunier and Espesser, 2011). Therefore, we analyzed consonant responses as a function of the class of the word in which the consonant was located, that is, in content words (nouns, adjectives, verbs, adverbs) and function words (pronouns, prepositions, conjunctions, and interjections). It was assumed that less acoustic features would be identified in consonants produced in function words than those produced in content words.

\section{Prosodic position}

There is no lexical stress in French and the prominence pattern mainly relies on the realisation of final lengthening (Delattre, 1966; Vaissière, 1991). Final lengthening is mainly governed by the syntactic word length and speaker's style (Fonagy, 1980, Vaissière, 1991). In addition to final stress, there is an optional non-emphatic initial stress which has a demarcative function (Astesano, 2001; Di Cristo, 2000; Fònagy, 1980; Pernot, 1929-30; Vaissière, 1974). Initial prominence has been specific to public styles (Vaissière, 1974) but is now spreading to nonpublic styles According to Fonagy (1989-2007), this initial prominence indicates a change in progress in the rhythmic structure of French. Our corpus consisted of read speech where the congruence between prosodic units and syntactic units is particularly strong (Vaissière and Michaud, 2005). Therefore, all syllables located at the edge of minor and major phrases (as defined by Blanche-Benveniste et al, 1990) were considered phrase-final syllables, either pre- 
pausal or non-pre-pausal. The first syllables of lexical words were considered as initial; syllables located within phrases were considered as non-final and non-initial. Syllables produced before a pause occurring within a phrase or within a word were excluded from the analysis (there were only eight cases). Therefore four locations were considered: consonants located in word-initial syllables, in final phrase syllables, followed by a pause and without a pause, and within non-initial and non-final syllables.

\section{Results \\ Statistical analysis}

All statistical tests were performed in the R software environment version 3.4.4 ( $\mathrm{R}$ Development Core Team, 2013). The linear mixed-effects model (lme package) was used to analyze the PPD scores considered as continuous data. As fixed effect, the speaker category (control vs patient) was systematically included to test the impact of this condition.

Differences with a p-value less than 0.05 were considered as significant. In order to illustrate the effect precisely, we reported the estimated value of means, standard deviations, F Values, degrees of freedom and p-value. When the difference was significant, we computed the $\underline{\text { Cohen's d parameter to obtain the effect size (package R 'effsize', function 'cohen.d'). If }}$ necessary in case of more than 2 levels in a factor, we computed Multiple Comparisons of $\underline{\text { Means by Tukey Contrasts ('glht' package) }}$

\section{Overall results}

As expected, the PPD score was significantly lower $(\underline{F(1,18)=10.49, p=0.0046} p<0.01)$ for healthy control speakers than for PD speakers. The mean score for the former was 0.72 with a standard deviation of 0.2 , the corresponding values for the latter were 1.18 and 0.42 . The effect 
$\underline{\text { is large }}(\underline{\text { Cohen's } d=1.38})$. These results, which can be seen in Figure 2 confirm the lower identification score of consonants in patient speech.

\section{INSERT FIGURE 2}

\section{Results by consonant}

As can be seen in Figure 3, there is an heterogeneity across consonants. Voiceless consonants such as /t, s, $\mathrm{J} /$ have the best identification score while the sonorants /m, n, l, R/ have low scores. The labiovelar/v/ and the sonorant /R/ have the lowest identification scores in both control and PD Speech. Patients have lower identification scores than controls, but interestingly this distribution is about the same for controls and patients.

\section{INSERT FIGURE 3}

\section{Results by speaker}

As can be seen in Figure 4, the PPD scores obtained for the healthy control speakers are grouped and inferior to 1 ; in contrast, there is a bimodal distribution for the patients, which suggests the existence of two groups. The first four patients had a low PPD score close to that of controls (less than 1) while the last six patients had a higher PPD score (superior to 1.25). Interestingly, the patients with a low degree of motor speech disorder $\left(\mathrm{UPDRS}_{\mathrm{speech}}=1\right.$; PARK1) have a low PPD score while the patients with a greater degree of severity of the disease $\left(\mathrm{UPDR}_{\text {speech }} \geq 2\right.$; PARK2 and PARK3 ) have a higher PPD score. Of course, we need to study more precisely this result with more than 10 patients, but we can put forward the idea that the PPD score is a good candidate to predict the severity of the speech disorder in Parkinson's disease.

\section{$\underline{\text { INSERT FIGURE } 4}$}




\section{Oral/nasal vocalic context effect}

There is no effect of group $\underline{(\mathrm{F}(1,18)=2.35, \mathrm{p}=0.14)}$ but an effect of context $(\mathrm{F}(3,214)=7.61, \mathrm{p}=$ $\underline{0.0001)}$ and an interaction between the two factors $(F(3,214)=4.81, p=0.0029)$ (Figure 5). For the healthy control speakers, there is a clear difference between the NCN context and the other contexts. The mean PPD score is the highest $\left(\mu=1.41 ; \mathrm{s}_{d}=1.22\right)$ when the C's are flanked by two nasal vowels. In case of a preceding nasal vowel, the mean score is 0.79 with a standard deviation $\left(\mathrm{s}_{\mathrm{d}}\right)$ of 0.52 . When there is a following nasal vowel or a complete oral vowel context, the scores are about the same: the mean is 0.62 and the standard deviation 0.45 for the former, the corresponding values are $0.72(\mu)$ and $021\left(\mathrm{~s}_{\mathrm{d}}\right)$ for the latter. These resuls clearly reflect the coarticulatory effect of nasal vowels on stops in French. It is well known that voiced stops are changed into their nasal counterparts when they are in a nasal vowel environment, especially in casual speech: for example, the words "pendant" (during) are produced as [pãnã] and lendemain (to morrow) [lãnmẽ].

In contrast, there are no such differences and no coarticulatory effect for the patients. The mean score is the same when the context is totally nasal $\left(\mu=1.17, \mathrm{~s}_{\mathrm{d}}=0.75\right)$ and when the preceding consonant is nasal $\left(\mu=1.17, \mathrm{~s}_{\mathrm{d}}=0.67\right)$. When the vocalic context is totally oral the mean score of non-identified features is the highest $\left(\mu=1.22, \mathrm{~s}_{\mathrm{d}}=0.47\right)$, the lowest score is for consonants followed by a nasal vowel $\left(\mu=0.94, \mathrm{~s}_{\mathrm{d}}=0.51\right)$. This finding is in agreement with the assumption that there is hypernasality of PD patients.

\section{INSERT FIGURE 5}

\section{Word class}


The results reported in figure 6 show that consonants located in content words have a significantly better identification score than those located in function words in both groups $(\underline{F(1,98)}=14.24, p=0.0003)$. In the control group, the mean PPD scores are lower for consonants located within content words $\left(\mu=0.65, s_{d}=0.20\right)$ than for those located within function words $\left(\mu=0.86, s_{d}=0.35\right)$. The effect is medium (cohen's $\left.d=0.75\right)$. In the patient group, the mean scores are significantly higher $(\underline{\mathrm{F}(1,18)}=10.02, \mathrm{p}=0.0054)$, the corresponding scores for content words and function words are $1.28\left(\mathrm{~s}_{\mathrm{d}}=0.5\right)$ and $1.12\left(\mathrm{~s}_{\mathrm{d}}=0.45\right)$, respectively. The effect is $\underline{\text { small }(\text { Cohen's } d=0.33)}$. There is no interaction $(\underline{F(1,98)}=0.35, p=0.55)$

\section{INSERT FIGURE 6}

\section{Prosodic position}

Figure 7 exhibits the mean scores obtained for the effect of consonant position in sentences. It can be seen that the PPD scores are the highest for the consonants located within phrases in the control group $\left(\mu=0.92 ; \mathrm{s}_{d}=0.30\right)$ and the patient group $\left(\mu=1.35, \mathrm{~s}_{\mathrm{d}}=0.48\right)$. When the consonants are in final syllables, the scores are slightly higher in case of a following pause (CTRL : $\mu=0.41$, $\mathrm{s}_{\mathrm{d}}=0.30 ; \mathrm{PD}: \mu=0.82, \mathrm{~s}_{\mathrm{d}}=0.53$ ) than in the absence of pause (for CTRL $\mu=0.51, \mathrm{~s}_{\mathrm{d}}=0.36$; for PD $\left.\mu=1.01, \mathrm{~s}_{\mathrm{d}}=0.59\right)$. The scores obtained for the word-initial consonants are intermediate for controls $\left(\mu=0.62, \mathrm{~s}_{\mathrm{d}}=0.32\right)$ and patients $\left(\mu=1.16, \mathrm{~s}_{\mathrm{d}}=0.60\right)$. To summarize, two tendencies emerge from the present results : 1) consonants located in boundary position (IP, FF, FP) have a significantly higher identification score $(\underline{F(3,214,)}=23.2, p<0.0001)$ than consonants located within phrases_(confirmed by multiple comparisons) and 2) the identification scores are

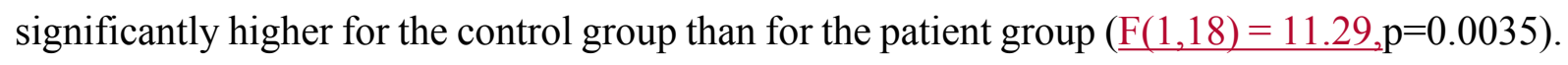
There is no interaction $(\underline{F(3,214)}=0.38, p=0.7653)$. 


\section{INSERT FIGURE 7}

\section{Discussion}

The present paper examined how consonants are affected by the disease and how this interacts with various linguistic factors. Different clear tendencies emerge from the current findings.

The first is the lower score of identification in PD speech compared to control speech. This expected result is in total accordance with the results reported in the literature on consonant imprecision: The differences reflect the articulatory problems that characterise PD's disease. Kinematic and electromyographic analyses of the articulatory deficit have revealed reduction in sound precision. For example, concerning plosives and fricatives, Logemann and Fisher (1981) stated that there was inadequate tongue elevation to achieve complete closure on stopplosives and affricates and there was also inadequate closed constriction of the airway in lingual fricatives. Both the incomplete contact for stops and the partial constriction for fricatives represent an inadequate narrowing of the vocal tract at the point of articulation. The reduced range of movement in PD patients can also be attributed to the rigidity of the jaw and scaling of speech movements. In summary, the sound imprecision in PD seems to result from the association of the reduced range of movement, the altered coordination of movement, and the rigidity of orofacial musculature, articulatory weakness (Goberman and Coehlo, 2002; Plowman-Prime, 2009).

The second is the heterogeneity of consonant scores in both groups: some of them had a high identification score, while it was the total opposite for the others. Different hierarchies have been proposed with consonant strength in inverse relation to the sonority scale such as the following elaborate hierarchy with voiceless stops and voiceless constrictives at the top, 
followed by voiced stops, voiced fricatives, nasals and laterals, and r-sounds, vowels being at the bottom (Jespersen, 1904; Vennemann, 1988). If we examine the scores obtained for the different consonants, we have the following hierarchy: 1) voiceless plosive /t/ and voiceless fricatives $/ \mathrm{s}, \mathrm{g} / ; 2$ ) voiceless plosives /p and $\mathrm{k} /$ and voiced stop $/ \mathrm{b}$ and $\mathrm{g} /$; fricatives $/ \mathrm{z}, \mathrm{3} /$; and 3 ) sonorants /m, n, 1,/; 4), the lowest scores are for the /R/ and the /v/.

If one excepts the $/ \mathrm{g} /$, the $/ \mathrm{R} /$ and the $/ \mathrm{v} /$ whose identification scores are much lower in PD individuals than in controls, a tendency to a similar hierarchy is observed in both groups. The hierarchies found for the groups are partly in agreement with the sonority hierarchy proposed in the literature. Sonorants are particularly sensitive to reduction processes and can become vowels, or be much more deleted (Duez, 1998), this may explain why they had the lowest identification scores in both groups. The voiceless occlusives and fricatives which are known to be changed into their voiced counterparts in PD speech had a rather high identification score, which may be due to a greater resistance and to their positions within words and phrases.

Interestingly, in control speech some consonants had some unidentified features. It is well known that speakers adaptively tune their phonetic gestures to the various needs of speaking situations (Lindblom, 1990) and that they maintain sufficient perceptual contrast (i.e. sufficiently rich contrast) in order to be understood. In the present study, consonants were extracted from their contexts, and the information retained in the consonant may not have been sufficiently rich for the identification of all the features. In addition, coarticulation has been shown to be frequent in VCV sequences (Öhman, 1966); moreover, spectrographic measurements revealed that many healthy control speakers occasionally spirantize stops and this occurs more frequently for certain positions-in-words (Weismer, 1984). Therefore, one may assume that some misidentified features were the result of contextual assimilation, misproductions or confusion. Concerning PD speech, there were probably anomalies due to the 
rigidity of muscles which leads to a reduction of the amplitude and/or the strength of articulatory movements.

The third result concerns the impact of nasal vowel context on consonants. In control speech, consonants followed by a nasal vowel had a better identification score of features than consonants preceded by a nasal vowel; when both followed and preceded by a nasal vowel the score was the lowest. This finding shows that carryover nasalisation is greater than anticipatory nasalisation. This is in line with the finding by Delvaux et al. (2008) that carryover nasalisation is more extensive than anticipatory nasalisation for both vowels and consonants in French. The results are quite different for PD speech since consonants flanked by oral vowels and consonants preceded and/or followed by nasal vowels had a similar low feature identification. There is much controversy in studies examining nasality in PD speech. For example, Darley et al. (1969) did not include nasality among the salient perceptual features of parkinsinian speech, Logemann et al. (1978) reported nasality in 10\% of PD patients, Hoodin and Gilbert (1989) did not report significant difference in nasality between PD and control speech. On the contrary, Ludlow and Bassich (1983) stated that nasality was a strong perceptual feature in differentiating PD speech and control speech. The results reported here suggest that there is nasalisation of consonants in PD speech whatever the vocalic context. this excess of nasality may reflect slow movement and rigidity of the muscles in the velopharyngeal mechanism (Duffy, 1995).

The impact of word class on consonant identification was the fourth main point examined. It was found that in control speech as well as in PD speech, consonants had more features identified in content words than in function words. This is in agreement with the studies on the phonetics of content and function words. For example, in a study of read Dutch speech, Van Bergem (1993) examined the acoustic form of function words and content words and demonstrated word stress and word class had a stronger effect on vowels than sentence accent; 
furthermore, the perceptual significance of the acoustic measurements was proved in a listening experiment. More recently, Meunier and Espesser (2011) investigated the role of lexical factors in the production of vowels extracted from a corpus of French conversations. They showed that vowels were more reduced in monosyllabic function words than in monosyllabic content words. Therefore, one may assume that as vowels, consonants were produced more clearly in content words than in function words in both groups. This fact is of interest because it suggests that patients, just as the healthy control speakers, tend to preserve the semantic information contained in lexical words.

The last point highlights the impact of the prominence pattern of utterances on the perception of consonants in both groups. The consonants located within-phrase syllables had a significantly lower identification score than the consonants located in prepausal-final syllables and non-prepausal-final syllables, suggesting that the former were produced less clearly than the latter. Patients have been shown to produce normal final lengthening as healthy control speakers; final-syllable vowels were proportionally lengthened more than final-syllable consonants in both parkinsonian speech and control speech, suggesting a progressive lengthening across the constituents of final syllables (Duez et al., 2009). One may assume that like healthy control speakers, patients more clearly articulate the segments of phrase-final syllables which are key points of the prosodic structure and have an important role in perception (Di Cristo, 2000). Interestingly, an effect of initial prominence on the identification of consonants was also observed. Initial prominence has been investigated acoustically and shown to be characterized by greater lengthening of the onset compared to final prominence which exhibits longer nucleus and rime (Jankowski et al., 1999; Hirst and al., 1998). This explains why word initial consonants had a better identification score than consonants located within phrases both in control and patient speech. Consonants produced in PD speech have been shown 
to be reduced and shortened compared to consonants produced in control speech in American English (Weismer, 1984) and French (Duez, 2009); however, despite this shortening, patients maintained the consonant lengthening which reflects initial prominence. This indicates that the syntactic and demarcative function of prosody is maintained in patients suffering from Parkinson's disease. This is in line with the finding that PD patients tend to preserve the information necessary to lexical stress perception (Darkins et al, 1988; Ackermann and Ziegler, 1991) and suggests there is no loss of linguistic knowledge in patients at least during the early and mild stages of the disease.

Finally, we think that the use of VCV sequences in the analysis of consonants in PD speech allowed us to focus on a certain number of characteristics of the intelligibility of PD speech. It is now extanded to a wider corpus of pathological speech where the VCV sequences which have been previously labeled are extracted automatically. A spectrographic investigation of consonants is also intended in order to relate perceptual data to spectrographic data and determine how patients and healthy control speakers produced the consonants, which features were the most fragile, how these features were distorted or reduced. This will also show how us accurately listeners interpret the acoustic information in the extracted consonants.

\section{Acknowledgements}

The authors would like to thank all of the participants to this study. We also thank Alain Purson and Ludovic Jankowksi for assisting with patient recordings. The authors thank the CEP staff (www.lpl-aix.fr/ cep), Laura Reynaud, and Carine André for assisting in perceptual experiment. The authors thank Rachael Renié-Phillips (SWIFT \& TRUE TRADUCTIONS) for her work on correcting English in the text. 


\section{Funding Sources}

This research was partially funded by LPL (BQR2017) and by the French National Research Agency ANR-18-CE45-0008 “Looking for relevant linguistic units to improve the intelligibility measurement of speech production disorders".

\section{Statement of Ethics}

This research was conducted ethically in accordance with the World Medical Association Declaration of Helsinki. All subjects (speakers and listeners) have given their written informed consent and the study protocol was approved by the institute's committee on human research.

\section{Disclosure Statement}

No Conflict of interest. 


\section{References}

Ackermann, H. and Ziegler, W (1991) Articulatory deficits in parkinsonian dysarthria: an acoustic analysis. J Neurol Neurosurgery Psychiatry, 54 (12), 1093-1098.

André C., Ghio A., Cavé C., Teston B. (2003) PERCEVAL: a Computer-Driven System for Experimentation on Auditory and Visual Perception. International Congress of Phonetic Sciences (ICPhS), pp.1421-1424. Barcelona, Spain 〈hal-00142980〉

Astésano, C. (2001) Rythme et Accentuation en Français: Invariance et Variabilité Stylistique. Paris : L'Harmattan.

Blanche-Benveniste, C., Bilger, M., Rouget, C., \& van den Eynde, K. (1990) Le français parlé. Etudes grammaticales. Sciences du langage Ps: Ed. du CNRS

Berns, J. (2013) Friction between phonetics and phonology. LOT Dissertation series

Bologna, M., Paparella, G., Fasano, A., Hallett, M. and Berardelli, (2020) Evolving concepts on bradykinesia. Brain, 143(3), 727-750.

Chenery, H., Murdoch, B. and Ingram, J. (1988) Studies in Parkinson's disease: 1 Perceptual speech analyses. Australian Journal of Human Communication disorders, 16(2), 17-29.

Chomsky, N. and Halle, M. (1968) The sound patterns of English, Harper \& Row (eds). New York.

Darkins, A, Fromkin, V. Benson, F. (1988) A characterization of the prosodic loss in Parkinson's disease, Brain and Language, 34(2), 315-327.

Darley, F.L, Aronson, A.E., Brow (1969) Differential diagnostic patterns of dysarthria, Journal of speech and hearing research, 12(2), 246-269.

Delattre, P. (1966) Studies in French and comparative phonetics. London, The Hague, Paris: Mouton Publishers.

Delvaux,V., Demolin, D., Harmegnies, b., Soquet, A. (2008) The aerodynamics of nasalization in French. Journal of Phonetics, 36(4), 578-606 
Di Cristo, A. (2000) Vers une modélisation de l'accentuation en français. Journal of French Language Studies, 9(2), 143-179.

Duez, D. (1995) On spontaneous French speech: Aspects of the reduction and contextual assimilation of voiced stops. Journal of Phonetics, 23(4), 407-427

Duez, D. (1998) Consonant sequences in spontaenous speech. SPoSS, pp. 60-66. Aix en Provence: ISCA workshop.

Duez, D. (2001) Restoration of deleted or assmilated consonant sequences in conversational French speech : effects of preceding and following contexts. Journal of International Phonetic Association, 31, 101-114.

Duez, D. (2009) Segmental Duration in Parkinsonian French Speech. Folia Phoniatrica and Logopaedica, 61(4), 239-46

Duez, D. (2014) Some segmental and prosodic aspects of speech motor disorders. In N.Miller and AL Lowit (Eds), Motor Speech Disorders : a Cross-language perspective (pp.168-195). Bristol, Buffalo, Toronto: Mulitlingual matters

Duez, D., Legou, T. and Viallet, F. (2009) Final lengthening in Parkinsonian French Speech: Effects of position in phrase on the duration of CV syllables and speech segment. Clinical Linguistics and Phonetics, 23(11), 781-793.

Duffy, J. (1995) Speech Motor Disorders : substrates, differential diagnosis, and management. Mosby: ST Louis.

Fahn S, Elteon RL (1987) UPRDS Dev Committee: The Unified Parkinson's Disease Rating Scales. In Fahn S, Marsden CD, Calnen DB,et al. (Eds), Recent Developments in Parkinson's Disease (pp.153164). New Jersey: MacMillan Healthcare Information.

Fisher, H.B. and Logemann, J.A. (1971) The Fisher-Logemann test of articulation competence, Austin, Texas, Pro-ED.

Fonagy, I. (1980) L'accent en français : accent probabilitaire..In I. Fonagy, P.Léon, F.Cartin (Eds), $L$ 'accent en français contemporain. Studia Phonetica XV. Ottawa, Paris, Toronto : Didier.

Fonagy, I. (1989) Le français change de visage. Revue Romane, 24(2), 225-254. 
Fonagy, I. (2007) Dynamique et changement. Editions Peeters : Louvain-Paris.

Foss, D.J.(1969) Decision process during sentence comprehension . Ef fects of lexical item dif ficulty and position upon decision times. Journal of Verbal Learning and Verbal Behavior, 8(4), 457 - 462 .

Fowler, C.A. and Housum, J. (1987) Talkers' signaling of "new" and "old" words in speech and listeners' perception and use of the distinction. Journal of memory and language, 26(5), 489-504.

Ghio, A., Pouchoulin, G., Teston, B., S Pinto, S., Fredouille, C., De Looze, C. (2012) How to manage sound, physiological and clinical data of 2500 dysphonic and dysarthric speakers? Speech Communication, 54 (5), 664-679

Ghio A, Lalain M, Giusti L, Fredouille F, Woisard V. (2020) How to Compare Automatically Two Phonological Strings: Application to Intelligibility Measurement in the Case of Atypical Speech. 12th Conference on Language Resources and Evaluation (LREC 2020), ELRA, May 2020, Marseille, France. pp.1682-1687. 〈hal-02482615v2〉

Goberman, AM and Coelho, C. (2002) Acoustic analysis of parkinsonian speech I: speech characteristics and L-Dopa therapy. NeuroRehabilitation, 17(3), 237-46.

Gremy, F. (1958) Contribution à l'étude oscillographique de certaines dysarthries. Paris: Thèse de Médecine. Paris. See http://Karger.com/article/pdf/263774.

Houdin, R.B. and Gilbert, H.R. (1989 Nasal airflow in parkinsonian speakers. Journal of Communication Disorders, 22(3), 169-180

Hirst, D., Astésano, C., Di Cristo, A. (1998) Differential lengthening of syllabic constituents in French: the effect of accent type and speaking style. 5th International Conference on Spoken LanguageProcessing(ICSLP) Sydney, ISCA Archive

Ho, A.K, Iansek, R., Marigliani, C., Bradshaw, J.L., Gates, S. ( 1999) Speech Impairment in a large sample of patients with Parkinson's disease. Behavioural Neurology, 11 (3), 131-137.

Hunnicut, S. (1985) Intelligibility versus redundancy : conditions of redundancy. Language and Speech. 28(1), 47-56.

Jankowski, L., Astesano, C.,Di Cristo, A. (1999) The initial Rhythmic Accent in French: Acoustic data and perceptual investigation. 14th International Congress of Phonetic Sciences, San Francisco, 257-260 
Jespersen, O. (1904) Lehrbuch der phonetik. Leipzig and Berlin.

Johnson, K. (2004) Massive reduction in conversational American English. In K. Yoneyama \& K. Maekawa (eds.) Spontaneous Speech: Data and Analysis. Proceedings of the 1st Session of the 10th International Symposium. Tokyo, Japan, 29-54.

Kent, R.D. and Netsell, R. (1971) Effects of stress contrasts on certain articulatory parameters, Phonetica, 24(1), 23-44.

Kent, R.D. and Rosenbek, J.C. (1982) Prosodic disturbance and neurologic lesion. Brain and Language, 15(2) 259-291.

Kent, R.D, Weismer, G. and Kent, J. (1989) Toward phonetic intelligibility testing. Journal of Speech and Hearing Disorders, 54, 482-499.

Lalain, M., Ghio, A., Giusti, L., Robert, D., Fredouille, C. and Woisard, V. (2020) Design and Development of a Speech Intelligibility Test Based on Pseudowords in French: Why and How? Journal of Speech, Language, and Hearing ResearchResearch, 63(7),2070-2083.

Lieberman, P. (1963) Some Effects of Semantic and Grammatical Context on the Production and Perception of Speech. Language and Speech, 6(3). 172-187.

Lindblom, B (1990) Explaining phonetic variation : a sketch of the H\&H. In Hardcastle and Marchal (Eds), Theory in Speech production and speech modelling (pp.403-439) Kluwer Academic Publishers.

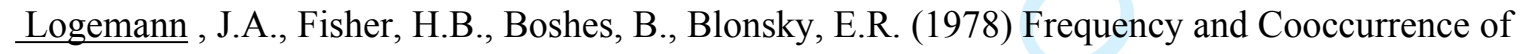
Vocal Tract Dysfunctions in the Speech of a Large Sample of Parkinson Patients. Journal of Speech and Hearing Disorders Research, 43(1), 47-57.

Logemann, J.A., Fisher, H.B. (1981) Vocal tract control in Parkinson's disease: phonetic feature analysis of misarticulations. Journal of Speech and Hearing Disorders, 46(4):348-52.

Ludlow, C and Bassich, C (1983) The results of perceptual assessment of two types of dysarthria. In W. Berry (Ed), Clinical Dysarthria, pp.121-153. San Diego: College-Hill press.

Meunier, C. and Espesser, R. (2011) Vowel reduction in conversational speech in French: the role of lexical factors. Journal of Phonetics, 39 (3), 271-278. 
Novotný, M., Rusz J., Čmejla R., Růžičková, H., Klempíŕ, J., Růžička' (2016) Hypernasality associated with basal ganglia dysfunction: evidence disease from Parkinson's disease and Huntington's. $\underline{\text { PeerJ }}$.

Öhman, S. E. G. (1966) Perception of Segments of VCCV Utterances. Journal of the Acoustical Society of America, 40(5), 979-88.

Parveen, S. and Goberman, A.M. (2014) Presence of stop bursts and multiple bursts in individuals with Parkinson disease. International Journal of Speech-Language Pathology, 16:5, 456-463, DOI: 10.3109/17549507.2013.808702

E.K Plowman-Prine, E.K., M.S. Okuna, M.S., C.M. Sapienza,, C.M., R. Shrivastav, R., H.H. Fernandez, H.H., Footed, K.D., Ellise, C., Rodriguez, A.D., Burkheadgand, L.M. and Rosenbek, J.C. (2009) Perceptual characteristics of Parkinsonian speech: A comparison of the pharmacologicaleffects of levodopa across speech and non-speech motor systems. NeuroRehabilitation, 24(2), 131-144.

Pernot, H. (1929-1930) L’intonation. Revue de Phonétique, 6, 273-289.

Pollack, I. and Pickett, J.M. (1963) The Intelligibility of Excerpts from Conversation. Language and Speech, 6(3), 167-171.

Pollack, I., \& Pickett, J. M. (1964) Intelligibility of excerpts from fluent speech: auditory vs. structural context. Journal of Verbal Learning \& Verbal Behavior, 3(1), 79-84.

Read, J., Miller, N. and Kitsou, N. (2018) Is there an order of loss of sounds in speakers with Parkinson's disease? Clinical Linguistics and Phonetics, 32(11), 997-1011.

Ruhlen, M., (1975) A Guide to the Languages of the World, Stanford, California, Stanford University Press

Uziel, A., Bohé, M., Uziel A. · Bohe M. · Cadilhac J. · Passouant P. (1975) Les troubles de la voix et de la parole dans les syndromes parkinsoniens. Folia Phoniatrica and Logopaedica, 27, 166-176.

Vaissière, J. (1974) On French prosody. Quaterly Progress Report, Research Laboratory of Electronics, Massachusetts Institute of Technology, pp.212- 20

Vaissière, J. (1991) Rhythm, accentuation and final lengthening in French. In R. Carlson and Granstrom (Eds) Music, Language and Brain (pp.108-120). Houndsmills: Macmillan. 
Vaissière, J., \& Michaud, A. (2005) Prosodic constituents in French: a data-driven approach. In I. Fonagy, Y.Kawaguchi, \& T. Moriguchi (Eds), Prosody and Syntax, (pp. 47-64). Amsterdam: John Brujamm.

Van Bergem, D. R. (1993) Acoustic vowel reduction as a function of sentence accent, word stress and word class. Speech communication, 12(1), 1-23.

Vennemann, t. (1988) Preference laws for syllable structure and the explanation of sound change. Berlin : Mouton de Gruyter.

Weismer, G. (1984) Articulatory characteristics of Parkinsonian dysarthria: Segmental and phrase-level timing, spirantization, and glottal-supraglottal coordination. In M.R. McNeil, J.C. Rosenbek \& A.E. Aronson (Eds.) The dysarthrias: Physiology, acoustics, perception, management (pp. 101-130). San Diego: College-Hill Press.

Whitefield, J. A., Reif, A. and Goberman, M. (2017) Voicing contrast of stop consonant production in the speech of individuals with Parkinson disease ON and OFF dopaminergic medication. Clinical Linguistics and Phonetics, DOI: 10.1080/02699206.2017.1387816 
Table 1. Number of occurences of consonants in the corpus as a function of articulation manner and voicing in normal and patient's speech

\begin{tabular}{|c|c|c|c|c|c|c|c|c|c|c|c|c|c|c|c|c|}
\hline \multicolumn{3}{|c|}{$\begin{array}{l}\text { unvoiced } \\
\text { occlusives }\end{array}$} & \multicolumn{3}{|c|}{ voiced occlusives } & \multicolumn{3}{|c|}{$\begin{array}{l}\text { unvoiced } \\
\text { fricatives }\end{array}$} & \multicolumn{3}{|c|}{ voiced fricatives } & \multicolumn{4}{|c|}{ Sonorants } & \multirow{2}{*}{$\begin{array}{l}\text { Class } \\
\text { Cons }\end{array}$} \\
\hline $\mathrm{p}$ & $\mathrm{t}$ & k & $b$ & $d$ & g & $f$ & s & s & v & z & 3 & $\mathrm{~m}$ & $n$ & I & $r$ & \\
\hline 77 & 110 & 77 & 67 & 72 & 30 & 30 & 112 & 68 & 28 & 62 & 45 & 57 & 85 & 187 & 71 & Control \\
\hline 75 & 104 & 75 & 67 & 73 & 28 & 29 & 93 & 69 & 22 & 54 & 44 & 54 & 78 & 172 & 54 & Patient \\
\hline
\end{tabular}


Table 2. Patient characteristics. . The motor disability of each patient was assessed by means of Unified Parkinson's disease rating scale (UPDRS III). Dysarthria severity was estimated with item 18 of the UPDRS: 0: normal; 1: slight loss of expression, diction, and/or volume; 2: monotone, slurred, but understandable, moderately impaired; 3: marked impairment, difficult to understand; 4: unintelligible.

\begin{tabular}{ccccc}
\hline & $\begin{array}{c}\text { Age of } \\
\text { diagnosis }\end{array}$ & $\begin{array}{c}\text { Years of post-PD } \\
\text { diagnosis }\end{array}$ & UPDRS III & $\begin{array}{c}\text { Dysarthria } \\
\text { severity }\end{array}$ \\
\hline P1 & 48 & 20 & 61 & 3 \\
P2 & 45 & 12 & 34 & 2 \\
P3 & 59 & 6 & 40 & 3 \\
P4 & 31 & 13 & 30 & 1 \\
P5 & 48 & 26 & 53 & 3 \\
P6 & 39 & 11 & 30 & 3 \\
P7 & 45 & 8 & 42 & 2 \\
P8 & 52 & 8 & 44 & 1 \\
P9 & 54 & 15 & 40 & 1 \\
P10 & 55 & 11 & 35 & 1 \\
\hline
\end{tabular}


Table 3 Allocation of blocks according to listeners

\begin{tabular}{|l|c|c|c|c|c|c|c|c|c|c|}
\hline Listener & $\mathrm{A}$ & $\mathrm{B}$ & $\mathrm{C}$ & $\mathrm{D}$ & $\mathrm{E}$ & $\mathrm{F}$ & $\mathrm{G}$ & $\mathrm{H}$ & $\mathrm{I}$ & $\mathrm{J}$ \\
\hline Blocks & 123 & 456 & 789 & 101112 & 131415 & 161718 & 19201 & 234 & 567 & 8910 \\
\hline Listener & $\mathrm{K}$ & $\mathrm{L}$ & $\mathrm{M}$ & $\mathrm{N}$ & $\mathrm{O}$ & $\mathrm{P}$ & $\mathrm{Q}$ & $\mathrm{R}$ & $\mathrm{S}$ & $\mathrm{T}$ \\
\hline Blocks & 111213 & 141516 & 171819 & 2012 & 345 & 678 & 91011 & 121314 & 151617 & 181920 \\
\hline
\end{tabular}



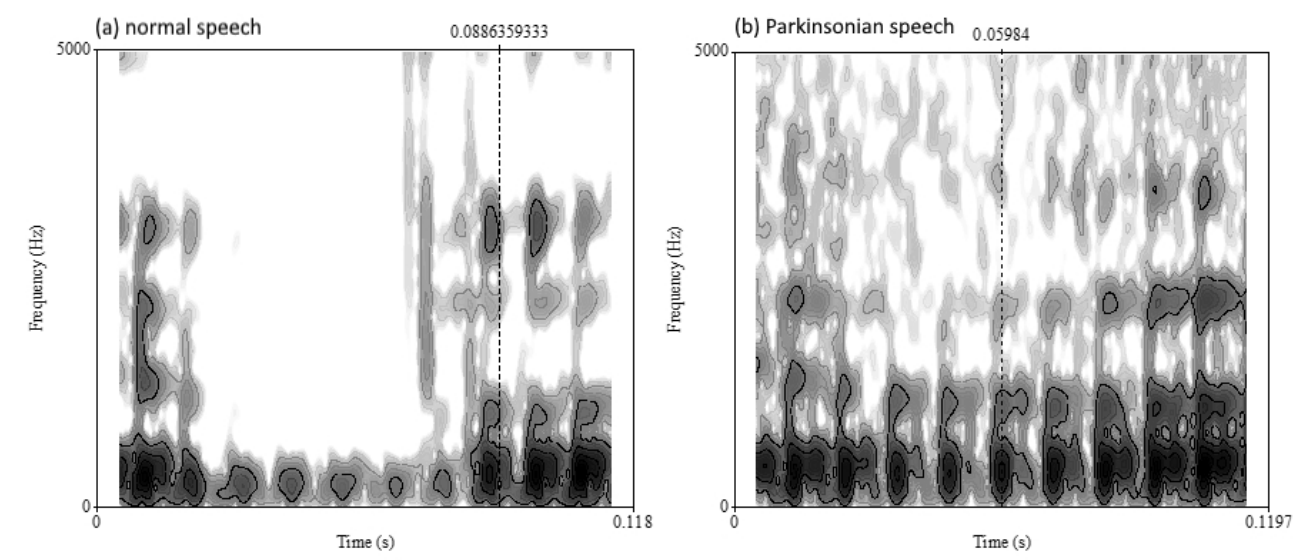

Figure 1 : Spectrograms of two /b/'s excised from normal speech (a) and Parkinsonian speech (b). In the former, one can see the occlusion and the burst ; in the latter, one can observe the presence of formants, which suggests that the consonant had become an approximant 


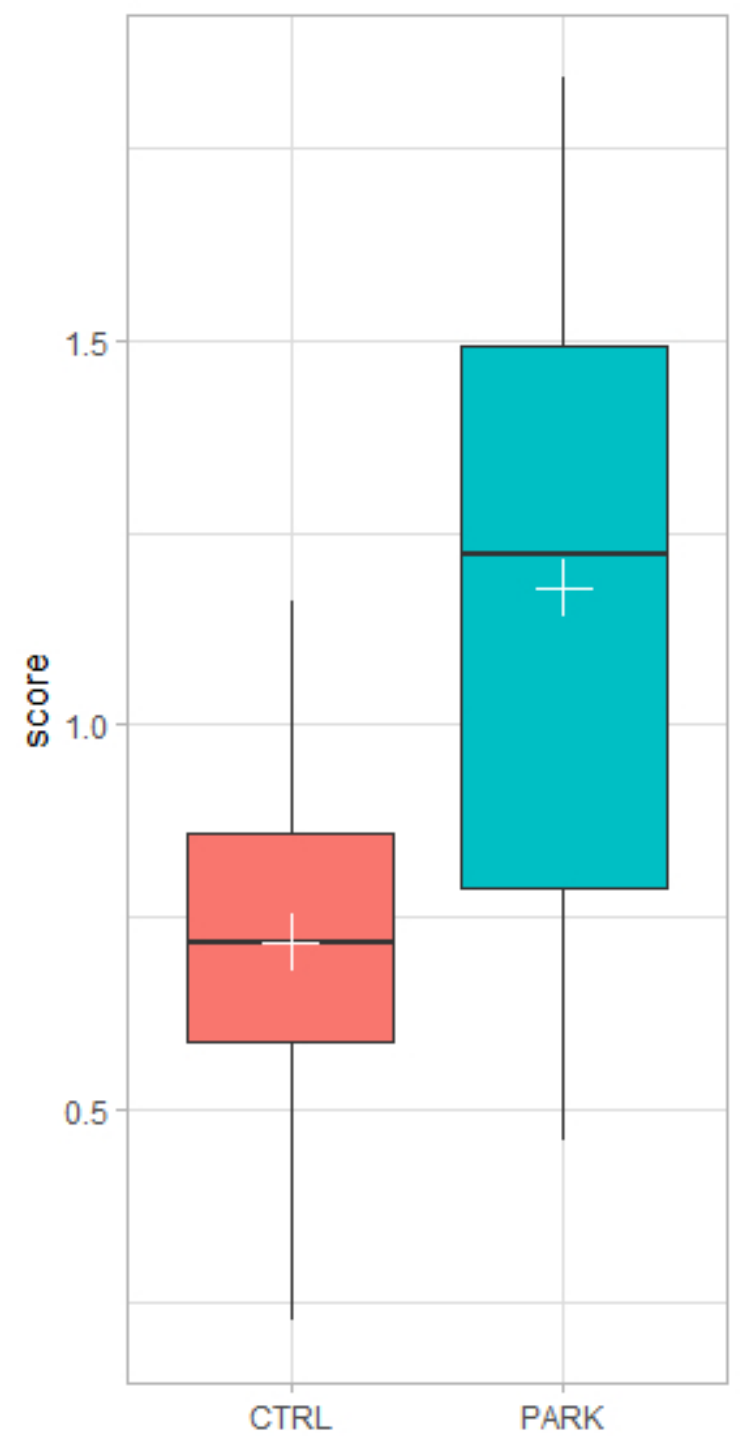

PPD scores for healthy speakers (CTRL) and PD speaksers (PARK). Black horizontal line is median. White cross is the average value. 


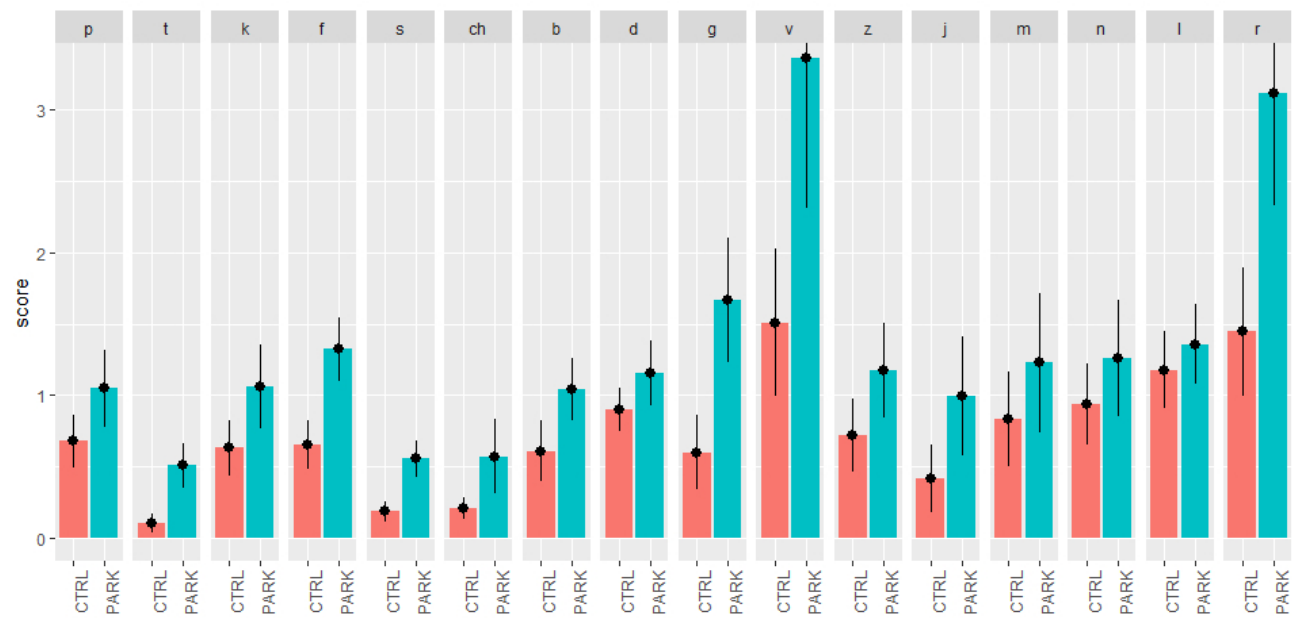

PPD scores for each consonant in the patient group (PARK) and the control group (CTRL). The errorbar is the $95 \%$ standard confidence interval of the mean. 


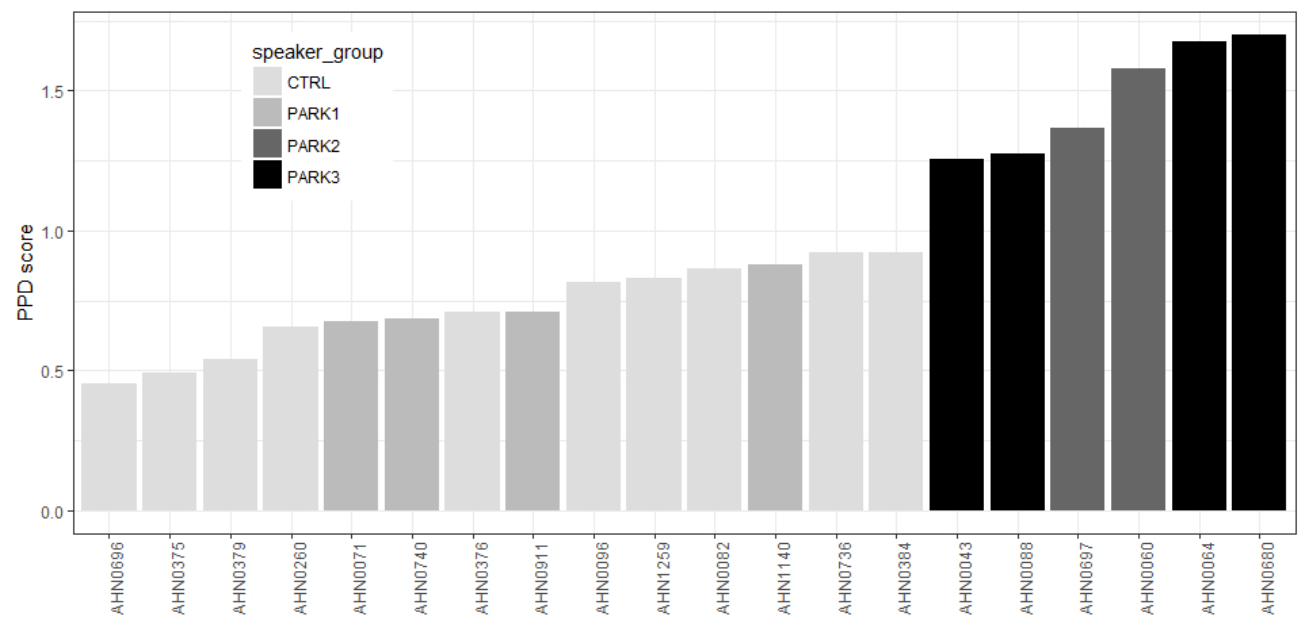

Figure 4. Individual PPD scores by speaker: healthy (CTRL) and patient (PARK). Patients are divided in 3 subgroups $(1,2,3)$ according to their UPDRS score on Speech (PARK1 = Slight loss of expression, diction and/or volume; PARK2 = Monotone, slurred but understandable; moderately impaired; PARK3= Marked impairment, difficult to understand (Fahn et al., 1987) 


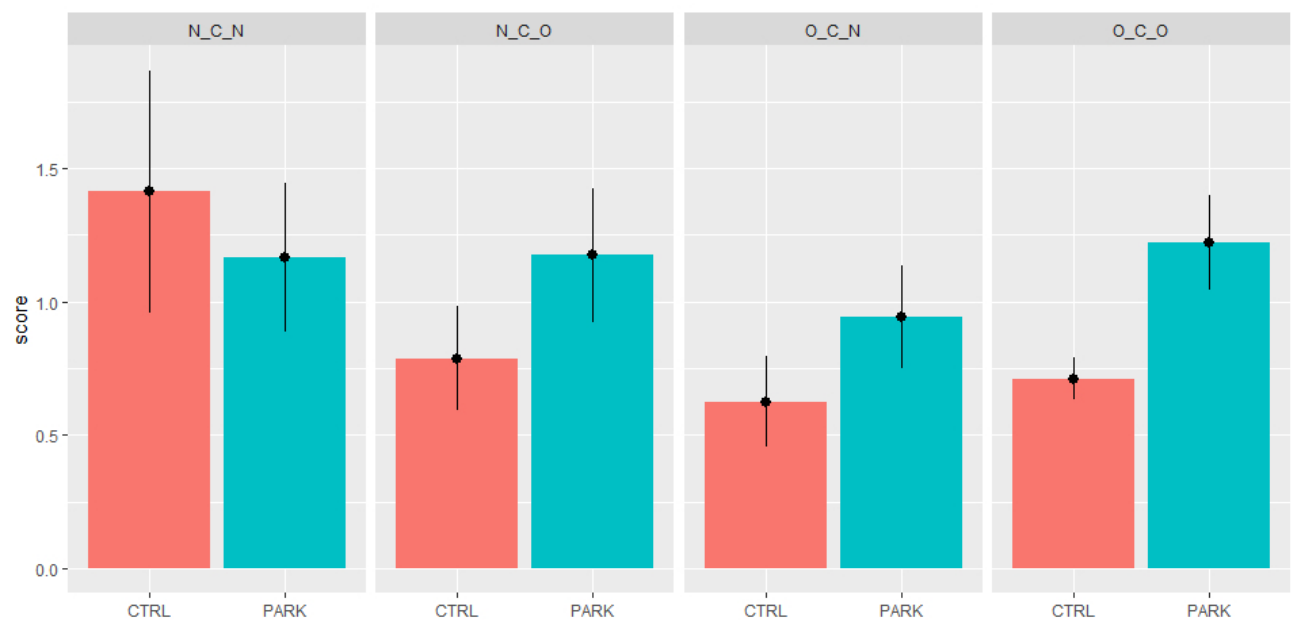

Figure 5. PPD scores features as a function of the nasal/oral vocalic context . N-C-N = consonants flanked by two nasal vowels, $\mathrm{N}-\mathrm{C}-\mathrm{O}=$ preceded by a nasal vowel and followed by an oral vowel, $\mathrm{O}-\mathrm{C}-\mathrm{N}=$ preceded by an oral vowel and followed by a nasal vowel, $\mathrm{O}-\mathrm{C}-\mathrm{O}=$ flanked by two oral vowels. Scores are for Parkinsonian speech (PARK) and for control speech (CTRL). The errorbar is the 95\% standard confidence interval of the mean 

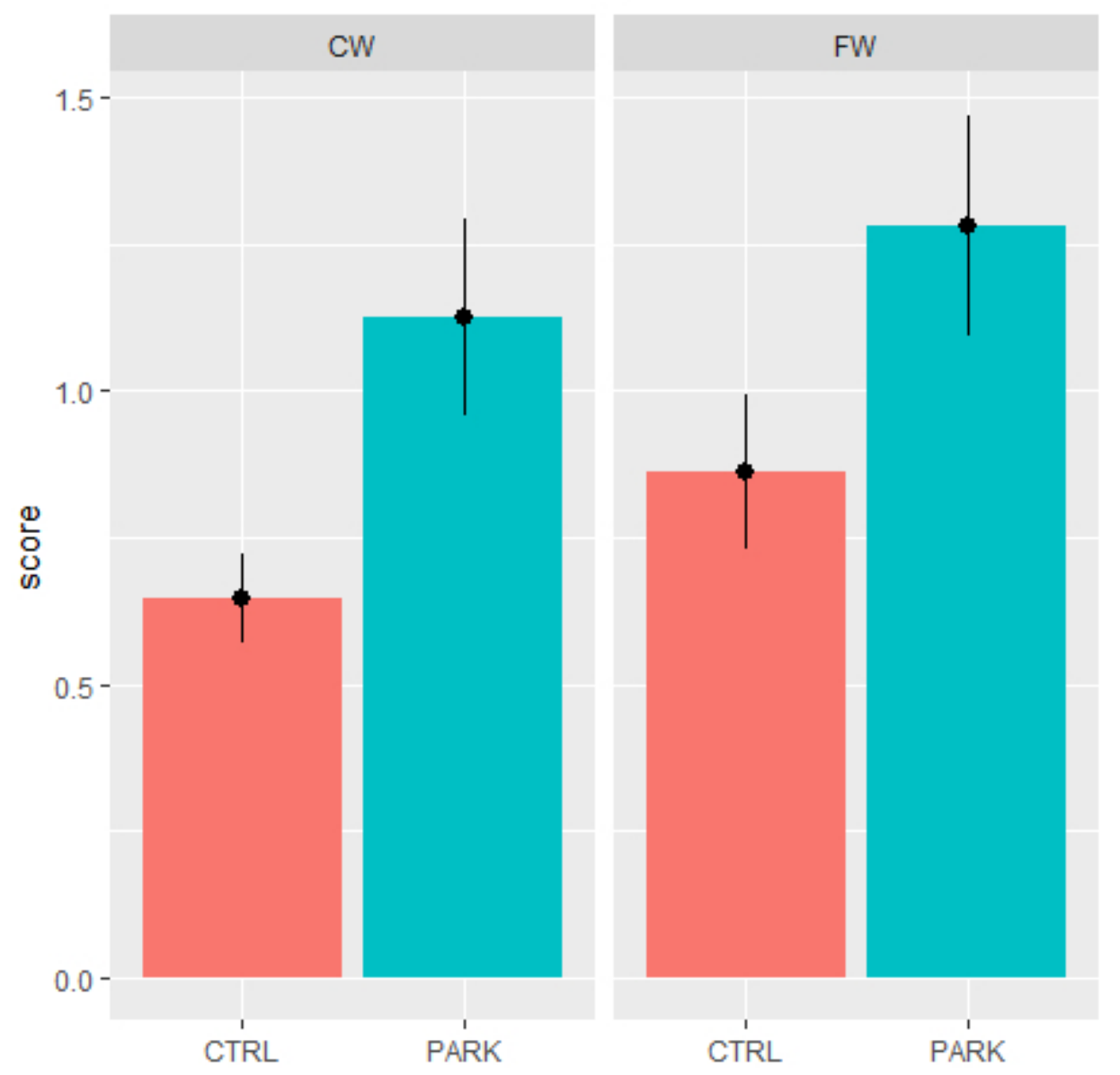

Figure 6. PPD scores for consonants in content words (CW) or in function words (FW) in control speech (CTRL) and Parkinsonian speech (PARK). The errorbar is the $95 \%$ standard confidence interval of the mean. 


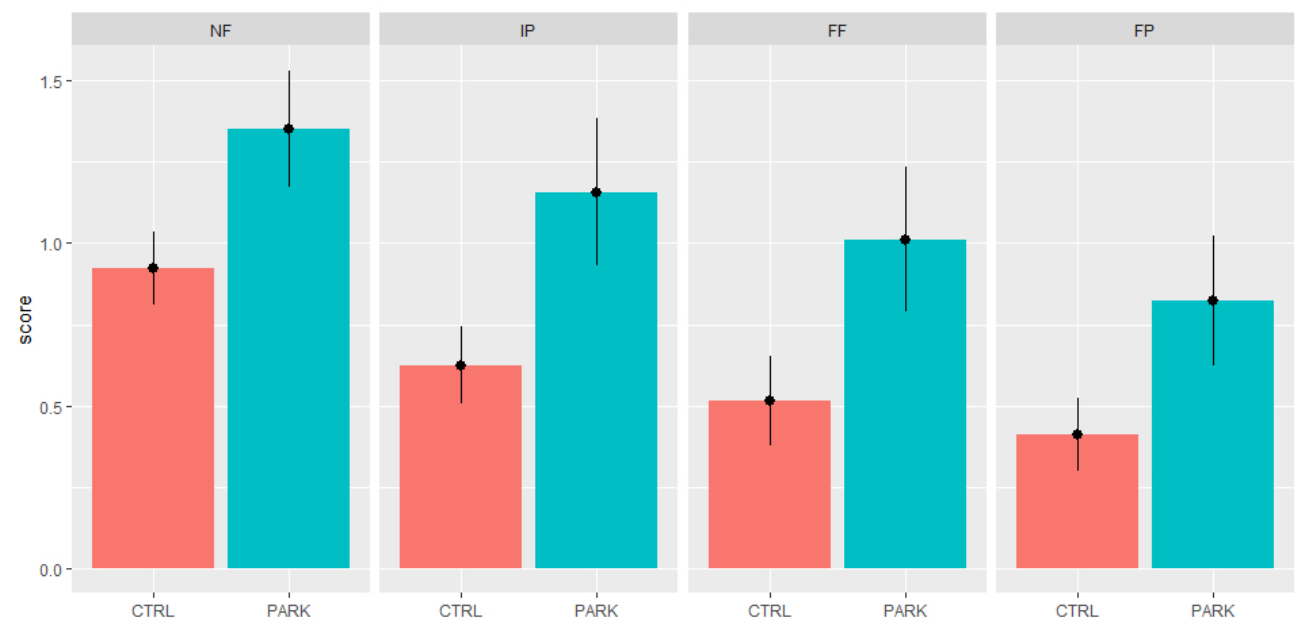

Figure 7. PPD scores of consonants located in non-final syllables (NF), non-prepausal phrase-final syllables (FF), prepausal-final-phrase syllables (FP) and in word-initial syllables (IP) 